\title{
Correction to: Single-Machine Order Acceptance and Scheduling Problem Considering Setup Time and Release Date Relations
}

\author{
Papatya S. Bıçakcı ${ }^{1}$ (i) $\cdot$ İmdat Kara ${ }^{2} \cdot$ Müjgan Sağır ${ }^{3}$
}

(c) King Fahd University of Petroleum \& Minerals 2021

\section{Correction to: Arabian Journal for Science and Engineering https://doi.org/10.1007/s13369-020-04759-1}

The original version of this article unfortunately contained an error in Equation (9). The correct version of Eq. (9) is given below.

Correct version:

$$
\sum_{j=1}^{n+1} Z_{i j}-\sum_{k=0}^{n} Z_{k i} \geq \sum_{j=1}^{n+1}\left(s_{i j}+p_{j}\right) X_{i j} \quad i \neq j, \forall_{i}=1, \ldots, n
$$

The original article can be found online at https://doi.org/10.1007/ s13369-020-04759-1.

Papatya S. Bıçakcı

papatyas@baskent.edu.tr; papatyasbicakci@gmail.com

1 Department of Management, Faculty of Economic and Administrative Sciences, Başkent University, Ankara, Turkey

2 Department of Industrial Engineering, Faculty of Engineering, Başkent University, Ankara, Turkey

3 Department of Industrial Engineering, Faculty of Engineering and Architecture, Osmangazi University, Eskisehir, Turkey 